\title{
Standardized Assessment of Concussion in football players
}

\author{
M. McCrea, PhD; J.P. Kelly, MD; J. Kluge, PT/ATC; B. Ackley, BA; and C. Randolph, PhD
}

\begin{abstract}
Article abstract-The recent formulation of guidelines for the management of concussion in sports adopted by the American Academy of Neurology specifically calls for the development of a standardized, systematic sideline evaluation for the immediate assessment of concussion in athletes. The present study involved the preliminary investigation of the feasibility and clinical validity of a standardized version of a brief sideline examination complied in accordance with these guidelines. This examination, intended for use by athletic trainers, was administered by three trainers to 141 nonconcussed high school football players at three separate schools. All players suspected of suffering a concussion $(N=6)$ during the fall 1995 season were also tested immediately following their injury. The examination was easily administered and scored. The concussed players as a group scored significantly below the nonconcussed controls and below their own baseline (pre-injury) performance, despite their all having been considered by the trainers to have suffered mild, grade 1 concussions. Although preliminary, these data suggest that a standardized sideline examination of this type can be useful in detecting concussion and determining fitness to return to play.
\end{abstract}

NEUROLOGY 1997;48:586-588

Brain injury suffered in organized sports has been the focus of increasing attention from medical personnel responsible for the care of athletes and administrative bodies in charge of various sports. In 1991 the Colorado Medical Society published Guidelines for the Management of Concussion in Sports ${ }^{1}$ as recommendations for the management of head injury in athletes, and the American Academy of Neurology $(\mathrm{AAN})^{2}$ adopted a revised version. The AAN Practice Parameter $^{2}$ also specifically calls for the development of a valid standardized systematic evaluation designed for use by athletic trainers and similar personnel during competition in the immediate sideline assessment of players suspected of sustaining a concussion. The Colorado and AAN guidelines, in line with the concussion literature, ${ }^{3,4}$ stress that a sideline examination should test orientation and probe for deficits in attention, concentration, and memory. Previous studies have examined gross mental status changes $^{5}$ and follow-up neuropsychological test performance ${ }^{6}$ in football players following concussion. No prior studies have used a standardized technique for immediately administering a sideline cognitive examination to detect and characterize concussion in athletes.

The current study involved a preliminary investigation of the feasibility and clinical validity of a standardized version of a brief sideline examination compiled in accordance with the guidelines proposed by the AAN. ${ }^{2}$ We accomplished this by having ath- letic trainers administer the examination to a large sample of nonconcussive high school varsity football players, both during practice and games during the 1995 football season. In addition, all players suspected of having a concussion during the 1995 season were administered the examination immediately following the injury. We compared performance on the examination during practice and games, explored the sensitivity of the examination to concussion, and surveyed trainers regarding the potential utility and practicality of the examination.

Methods. Subjects. One hundred forty-one nonconcussed high school varsity football players from three separate schools in Iowa participated in the study during the 1995 football season. Seventy-six control players were tested during games and 65 during practice. Trainers were also requested to administer the examination to any player suspected of having suffered a concussion. Six players were identified by trainers as possibly having suffered a concussion, all during actual games. These were all classified by the trainers as grade 1 concussions (brief confusion, no loss of consciousness). Players and coaches typically refer to these as having been "dinged," or having had "their bell rung." All six players were tested by an athletic trainer immediately following the injury, and all six had previously been tested as controls, thereby establishing baseline performance measures against which mental status changes following the injury could be detected.

Examination. The sideline examination was designed according to the Colorado ${ }^{1}$ and AAN guidelines ${ }^{2}$ and contains four components: Orientation, Immediate Memory,

From Northwestern University Medical School (Drs. McCrea and Kelly, B. Ackley, and Dr. Randolph) and The Rehabilitation Institute of Chicago (Dr. Kelly), Chicago, IL; and Covenant Medical Center (J. Kluge), Waterloo, IA.

Received July 10, 1996. Accepted in final form December 24, 1996.

Address correspondence and reprint requests to Dr. Christopher Randolph, 111 N. Wabash, \#1021, Chicago, IL 60602. 


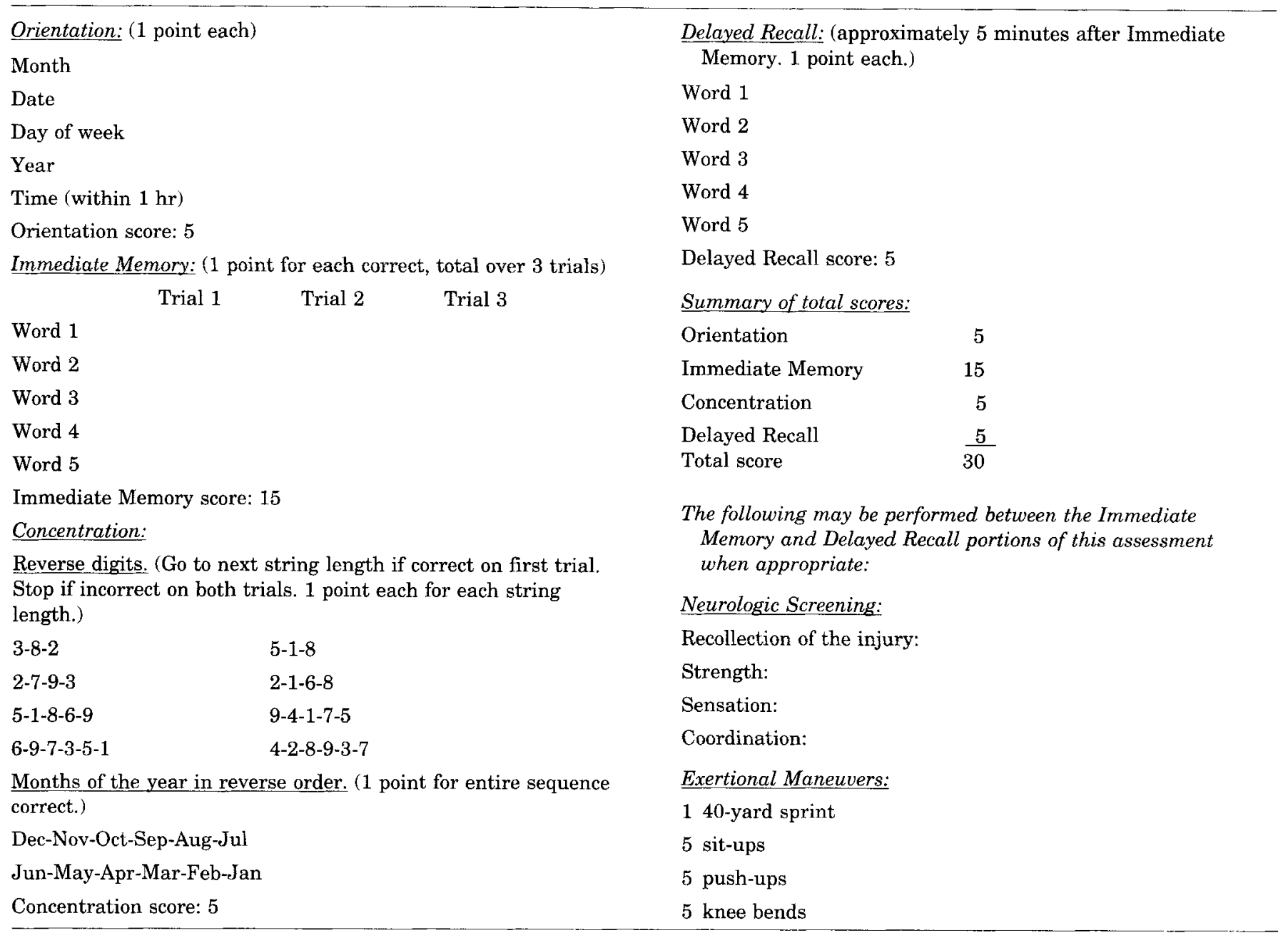

Concentration, and Delayed Recall (table 1). The maximum total score on the examination is 30 points. Trainers were also asked to record any asymmetries in pupil size, evidence of incoordination, or evidence of sensory abnormalities in any player suspected of having suffered a concussion. Three forms of the examination were designed to allow follow-up testing of concussive players while minimizing practice effects in order to track postconcussion recovery. The forms differ only in the stimulus selection of digits in the Concentration component and words used for memory testing. The examination required approximately 5 minutes to administer. One athletic trainer at each of the three participating schools was responsible for all aspects of examination administration and collection of data.

Results. One-way ANOVAs revealed no significant difference between total scores on examinations collected during practices and games. There was no significant difference between total scores on examination given by the three participating athletic trainers at separate schools by one-way ANOVA, nor was there a significant Pearson correlation between total score and age. The three forms of the test were found to be equivalent, with no significant difference in total score on ANOVAs comparing Forms A, B, and C.

The total score obtained by concussive players immediately following injury was significantly lower than that of the total nonconcussive sample $(\mathrm{F}[1,145]=18.4, p<$
0.0001 ). The mean total score of the concussive group was 1.84 standard deviations below the control group mean. Concussive players scored significantly lower than controls on the Immediate Memory $(p<0.0001)$ and Delayed Recall $(p<0.025)$ portions of the examination. No significant group effects were detected on the Orientation or Concentration components, although the group difference on the Concentration section approached significance. None of the concussed players exhibited any changes in neurologic measures (pupils, coordination, sensation), as reported by the trainers. Since all concussive players had been previously tested, actual changes against their nonconcussive baseline performance could be measured. A matched paired $t$ test revealed that, despite the small sample size, their mean total score was significantly lower postconcus$\operatorname{sion}(t[5]=2.7 ; p<0.05)$. The scores for both groups are presented in table 2 .

All three trainers were surveyed regarding the utility and practicality of the examination. All felt that it required little training to master and was easily administered on the sidelines in the context of game conditions.

Discussion. The results support the feasibility and preliminary clinical validity of this brief examination designed for use by athletic trainers in the immediate sideline screening of football players suspected 
Table 2 Summary of scores for normal and concussed players

\begin{tabular}{lccc}
\hline & $\begin{array}{c}\text { Controls } \\
(\mathrm{n}=141)\end{array}$ & $\begin{array}{c}\text { Concussed } \\
(\mathrm{n}=6)\end{array}$ & $p$ \\
\hline Orientation & $4.77(0.5)$ & $4.8(0.4)$ & 0.764 \\
Immediate Memory & $14.5(0.9)$ & $12.0(2.5)$ & $<0.0001$ \\
Concentration & $2.19(1.2)$ & $1.5(0.5)$ & 0.159 \\
Delayed Recall & $4.12(1.0)$ & $3.2(1.2)$ & 0.025 \\
Total score & $25.6(2.2)$ & $21.5(3.5)$ & $<0.0001$ \\
\hline
\end{tabular}

of concussion. Sideline testing during the games did not significantly disrupt the normal duties of medical and athletic training staff, and athletic trainers felt the examination was easy to administer. The three forms of the examination were equivalent, allowing for the reassessment of mental status and tracking of recovery while minimizing practice effects.

There was no significant difference between examinations conducted during games or practice, suggesting that baseline normative data collected on players during preseason practice are reliable and can be used to detect mental status changes secondary to concussion during actual game conditions. Although a formal investigation of inter-rater and testretest reliability was not part of this preliminary study, the fact that the mean examination scores for nonconcussed players were equivalent for all three trainers suggests that inter-rater reliability will prove to be adequate. Adequate investigation of testretest reliability would require a larger sample of concussed players, with multiple examiners immediately available. This was not within the scope of the present study.

Only six players had concussions during the course of this protocol, and all concussions were diagnosed by the athletic trainers as relatively mild, without overt evidence of significant neurologic dysfunction or disorientation. Nevertheless, total score on the examination was successful in differentiating control players from those with concussion. Specifically, the learning and delayed recall of the five-item word list were the two measures that differentiated players with mild concussion from controls. The standard Orientation testing was insensitive to mild concussion, as Maddocks et al. ${ }^{7}$ recently reported. Although the difference between the groups on the Concentration domain did not quite reach statistical significance, item analysis revealed that none of the concussive players correctly repeated either five or six digits backwards. This further emphasizes the utility, for detection of mild concussion, of employing slightly more demanding cognitive measures than are typically used in mental status examinations. ${ }^{1}$

Because all injured players had relatively mild concussions, we detected no differences in level of orientation or the presence of neurologic signs (at least as determined by the trainers) between control and concussive players. With more severe concussion, we would expect greater impairment on this test, with disorientation and sensory-motor abnormalities becoming apparent in increasingly severe injuries.

The data from the present study are preliminary, from a single geographic region, and involve only high school athletes. As such, no definitive guidelines or cutoff scores for interpreting performance on this examination can be presented. Ideally, perhaps the most sensitive means of utilizing this instrument is to collect baseline normative data on players during the off-season or preseason camp and then compare each injured player directly with this baseline performance in the event of concussion to determine the severity of injury and follow the player's recovery. We have designed and are undertaking studies to address the relative utility of this approach, in comparison with the use of population-based cutoff scores. Currently, we are collecting additional normative and reliability data as part of a multicenter study of football players on all competitive levels to confirm the clinical utility of this instrument. Together with the current AAN guidelines, the use of standardized examination will allow a more empirically determined approach to decision-making in the management of sports-related concussion, which sideline medical personnel have reported to be the most frequent problem they face. ${ }^{8}$

\section{Acknowledgments}

The efforts of the Athletic Training Staff at Covenant Medical Center, Waterloo, Iowa, in collecting our data during the 1995 season are greatly appreciated. The authors also acknowledge the coaching staff, players, and administration at Cedar Falls, Waterloo East, and Waterloo West High Schools for their cooperation and participation in the study.

\section{References}

1. Colorado Medical Society. Report of the Sports Medicine Committee: Guidelines for the management of concussion in sports (revised). Denver: Colorado Medical Society, 1991.

2. Kelly JP, Rosenberg J. Practice parameter: The management of concussion in sport. Report of the Quality Standards Committee. Neurology 1997;48:581-585.

3. Kelly JP, Nichols JS, Filley CM, Lillehei KO, Rubinstein D, Kleinschmidt-Demasters BK. Concussion in sports: guidelines for the prevention of catastrophic outcome. JAMA 1991;226:28672869.

4. Kelly JP. Concussion. In: Torg JS, ed. Current therapy in sports medicine. 3rd ed. Philadelphia: Mosby, 1995.

5. Yarnell PR, Lynch S. Retrograde memory immediately after concussion. Lancet 1970;1:863-864.

6. Barth J, Alves W, et al. Mild head injury in sports: neuropsychological sequelae and recovery of function. In: Levin HS, Eisenberg HM, Benton AL, eds. Mild head injury. New York: Oxford University Press, 1989.

7. Maddocks D, Dicker GD, Saling MM. The assessment of orientation following concussion in athletes. Clin J Sports Med 1995; $5: 32-35$

8. Landry G. Mild brain injury in athletes. In: Proceedings from Mild Brain Injury Summit, Washington, DC, April 16-18, 1994. National Athletic Trainers Association Research and Education Foundation. 